\title{
It's Time to Act on Supporting Public Engagement
}

\author{
The COVID-19 pandemic has revealed a systemic lack of support for the \\ public-engagement programs of physics departments, a trend that the \\ physics community should act to correct.
}

\author{
By Michael Bennett, Katie Hinko, and Dena Izadi
}

6 "I hated physics," is a response many physicists might be familiar with hearing after introducing themselves at a party or on a plane. Usually, the phrase is followed by the person describing some negative experience that they had with a physics coursework assignment in high school or college.

As physicists, we know that physics is so much more than the lackluster experiences that might be associated with formal education. That is why we, and many other physicists, engage with people outside of the field through informal education, or "outreach," or, as we prefer to call it, "public engagement." These efforts, which include public talks, experimental demonstrations, podcasts, and YouTube channels, help nonphysicists decouple their specific negative physics

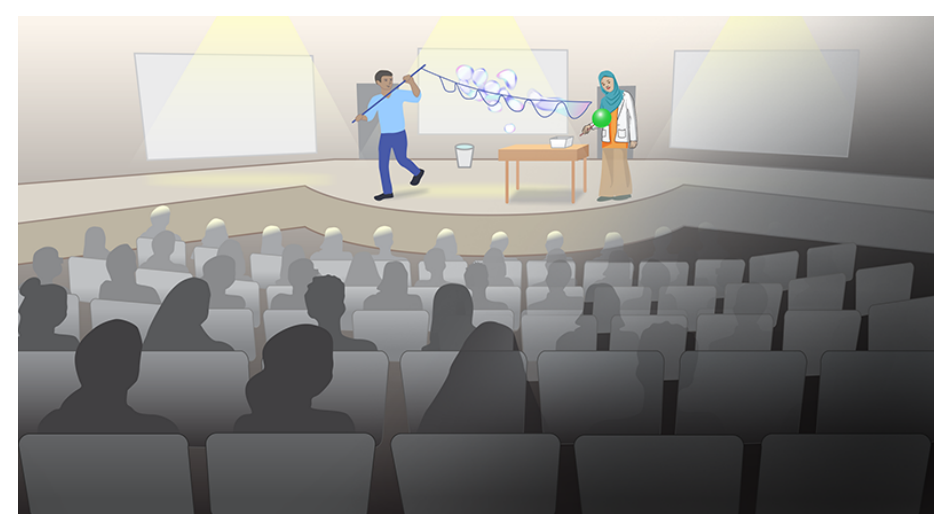

Many public engagement programs are at risk of disappearing, taking with them an essential communication pathway between physicists and society at large.

Credit: APS/Carin Cain experiences from the joy that the field as a whole can offer. These initiatives are also the main ways that nonphysicists come to understand what physicists do. But sadly, these activities are often undervalued by the departments that house them and-as observed during the COVID-19 pandemic-are at risk of disappearing entirely. Without increased support for public-engagement programs, physicists may lose an essential connection to society at large.

Public engagement by physicists has a long history. One early example is an 1825 lecture by Michael Faraday. (His talk was the first "Christmas Lecture" given at the Royal Institution in the UK, a tradition that continues today.) But these efforts are often fringe activities, occurring as pet faculty projects or "extracurricular" student activities, for example. What's more, the efforts are often one-off events, or they last only as long as a specific grant's funding.

Even in relatively small doses, public engagement activities can provide substantial, meaningful experiences for audience members and organizers alike: Audience members get to learn about current research efforts outside of the classroom and, importantly, both groups get to directly interact with each other, making personal connections. These interactions are often the only way audience members engage directly with physicists. In addition, our research has shown that when physics students organize and facilitate these events, they gain, among other things, improved science communication skills, opportunities for pedagogical practice, and a sense of community.

Despite these benefits, public engagement programs tend not to be treated as core activities within physics departments. This 
issue has become especially apparent over the last year and a half. In a study that we published today, we investigated the impact that the COVID-19 pandemic had on 15 U.S.-based public engagement programs housed at universities and science centers. Nearly all of the studied programs reported ceasing their regular activities shortly after the beginning of the U.S. COVID-19 lockdown in March 2020. For example, one program, which partnered with a local museum to host "science day" events, stopped such events entirely because social-distancing requirements meant that the museum venue couldn't be used. Distressingly, even as some semblance of "normal" life returns, the future of many of these programs remains uncertain-program directors for nine of the 15 programs that we studied doubted that they would recommence any of their traditional operations.

Our study did, however, uncover some good news-four of the programs that we studied thrived during the pandemic, expanding their activities. What set these programs apart was that they all had robust institutional support. All four of these programs were-and still are-supported both financially and logistically by either university-level institutions, dedicated national research grants, or both. As a result, these programs were able to adapt to the challenges of operating during a pandemic, such as loss of ticketing income and closure of venues.

Another conclusion of our study is that the ability of the public-engagement programs we studied to weather the COVID-19 storm directly depended on institutions maintaining their support. In a crisis, it may be tempting for department leaders to withdraw funding and focus on more "traditional" core activities. It is clear from our data, however, that public-engagement programs simply cannot survive in crisis conditions without this support: Once a program ceases activity, it loses its connection to the community and may lose its personnel and even its institutional memory, making it extremely challenging for that program to restart.

So, what can we all do to fix the problem? First and foremost, physicists need to treat engagement with nonphysicists as a core institutional and departmental activity. That change requires building funding options for engagement efforts directly into departmental budgets. Many physics departments already claim credit for engagement efforts in reports to funding agencies, so, we argue, they should also provide the needed resources to make those efforts robust. Departments also need to incentivize the involvement of faculty and staff in these programs, perhaps by making these activities a component of tenure review or by providing visible recognition to the staff and students who lead these programs. These actions would normalize participation in informal education efforts, rather than frame it as a distraction from the "true" work of research. We also argue that departments need to support research that evaluates public-engagement programs so that the field can develop a deep understanding of the long-term impact of its engagement efforts.

We are all members of the communities in which we live and work. If we want to change the perception of physics for those outside of the field, we need to change our own perceptions of the importance of engaging with nonphysicists and of the value of such efforts.

Michael Bennett: Q-SEnSE Quantum Leap Challenge Institute, University of Colorado, Boulder, CO, USA

Katie Hinko: Michigan State University, East Lansing, MI, USA

Dena Izadi: Michigan State University, East Lansing, MI, USA 